\section{SAT0546 SENSORINEURAL HEARING LOSS IN TAKAYASU'S ARTERITIS}

U. Kimyon ${ }^{1}$, S.N. Esatoglu' ${ }^{1}$, E. Kara ${ }^{2}$, A. Atas ${ }^{2}$, E.E. Gunay ${ }^{2}$, E. Karaman², E. D. Gozen ${ }^{2}$, V. Hamuryudan ${ }^{1}$, H. Yazici ${ }^{1}$, E. Seyahi ${ }^{1} .{ }^{1}$ Istanbul University, Cerrahpasa Medical School, Department of Internal Medicine, Division of Rheumatology, ${ }^{2}$ Istanbul University, Cerrahpasa Medical Faculty, Department of Otorhinolaryngology, Istanbul, Turkey

Background: Sensorineural hearing loss has been reported to be increased in several chronic autoimmune and non-autoimmune diseases such as systemic lupus erythematosus (SLE), progressive systemic sclerosis, rheumatoid arthritis, small vessel vasculitides, ankylosing spondylitis and Behçet's syndrome. We had sporadically noted several degrees of sensorineural hearing loss among our Takayasu's arteritis (TA) patients. While some revealed this in their past history, others had relapsing attacks of hearing loss independent of or associated with vascular relapses.

Objectives: We formally investigated the frequency and type of hearing loss among TA patients and suitable controls.

Methods: The study was done in two parts. In the first part, consecutive TA and SLE patients seen at outpatient clinic along with apparently healthy controls were administered a standardised questionnaire that assessed hearing loss, tinnitus, and episodic vertigo. In the second part, previously registered TA and SLE patients for another study were called to specifically for otological examination and audiometry tests that included pure-tone air and bone conduction, speech audiometry and acoustic reflex threshold test.

Results: In the first part, 73 patients with TA, 107 patients with SLE and 133 healthy controls were studied as shown in table 1 . The frequency of those with hearing deficit/loss, tinnitus and vertigo were significantly more common among both TA and SLE patients (table 1). While the frequency of those with hearing deficit/loss was similar in TA and SLE, those with tinnitus and vertigo were significantly more common in TA.

In the second part, 50 patients with TA, 22 patients with SLE and 32 healthy controls were studied as shown in table 2 . Audiometry tests revealed that several degrees of hearing loss were present in $36 \%$ of the patients with TA, $18 \%$ of the patients with SLE and $6.3 \%$ of the healthy controls $(p<0.05)$. This was mostly due to sensorineural hearing loss in TA patients (13/18) and high -frequency type was the most common pattern. Moreover, those TA patients with sensorineural hearing loss did not show any specific vascular pattern.

Abstract SAT0546 - Table 1. Results of the questionnaire survey

\begin{tabular}{|c|c|c|c|c|c|c|}
\hline & $\begin{array}{c}\text { Takayasu's } \\
\text { arteritis } \\
(n=73)\end{array}$ & $\begin{array}{r}\text { SL } \\
(n=1\end{array}$ & & $\begin{array}{l}\text { Healthy } \\
\text { controls } \\
(n=133)\end{array}$ & $p$ value & \\
\hline Mean age & $43.7 \pm 11.0$ & $44.0 \pm$ & & $42.5 \pm 8.3$ & & \\
\hline Disease duration, med [IQR] & $7^{3-12}$ & $8^{3-1}$ & & NA & & \\
\hline Hearing deficit/loss, n (\%) & $20(27.4)$ & $21(1$ & & $4(3.0)$ & 0.001 & \\
\hline Tinnitus, n (\%) & $37(50.7)$ & $34(3$ & & $16(12.0)$ & 0.001 & \\
\hline \multirow[t]{2}{*}{ Vertigo, $\mathrm{n}(\%)$} & $39(53.4)$ & $38(3$ & & $19(14.3)$ & 0.001 & \\
\hline & \multicolumn{2}{|c|}{$\begin{array}{l}\text { Takayasu's } \\
\text { arteritis, } \\
(\mathrm{n}=50)\end{array}$} & \multicolumn{2}{|c|}{$\begin{array}{c}\text { SLE } \\
(n=22)\end{array}$} & $\begin{array}{l}\text { althy controls } \\
\qquad(n=32)\end{array}$ & $p$ val \\
\hline Mean (SD) age & \multicolumn{2}{|c|}{$41.3 \pm 8.9$} & \multicolumn{2}{|c|}{$\begin{array}{c}42.1 \\
\pm 10.3\end{array}$} & $41.1 \pm 0.8$ & NS \\
\hline Disease duration, med [IQR] & \multicolumn{2}{|c|}{$6^{4-11}$} & \multicolumn{2}{|c|}{$7^{3-11}$} & - & NS \\
\hline Hearing loss, $\mathrm{n}(\%)$ & \multicolumn{2}{|c|}{$18(36.0)$} & \multicolumn{2}{|c|}{$4(18.1)$} & $2(6.3)$ & $<0.05$ \\
\hline Sensorineural type, $\mathrm{n}(\%)$ & \multicolumn{2}{|c|}{$13(26.0)$} & \multicolumn{2}{|c|}{$2(9.0)$} & $1(3.1)$ & \\
\hline Conductive type, n (\%) & \multicolumn{2}{|c|}{$5(10.0)$} & \multicolumn{2}{|c|}{$2(9.0)$} & $1(3.1)$ & \\
\hline
\end{tabular}

Conclusions: We are unaware of previous surveys of sensorineural hearing loss in TA. Our study shows that audiovestibular system is considerably affected in TA, similar to that observed in SLE. The fact that there was no clear vascular pattern among patients with hearing loss, suggest that small vessel vasculitis was probably the cause of this hearing loss.

Disclosure of Interest: None declared

DOI: 10.1136/annrheumdis-2018-eular.2962

\section{SAT0547 \\ PROGNOSTIC NUTRITIONAL INDEX FOR ESTIMATING BIRMINGHAM VASCULITIS ACTIVITY SCORE IN ANCA- ASSOCIATED VASCULITIS}

S.S. Ahn, J. Yoo, S.M. Jung, J.J. Song, Y.-B. Park, S.-W. Lee. Division of Rheumatology, Department of Internal Medicine, Yonsei University College of Medicine, Seoul, Korea, Republic Of

Background: The prognostic nutritional index (PNI), which was first introduced by Onodera et al., is calculated based on the serum albumin level and total lymphocyte count in the peripheral blood. It is proposed to be a parameter to reflect immunonutritional status, however, it is also known that albumin and lymphocyte count may decrease in proportion to inflammatory burdens in autoimmune diseases.

Objectives: We investigated whether $\mathrm{PNI}$ at diagnosis can be used for estimating BVAS at diagnosis in antineutrophil cytoplasmic antibody (ANCA) associated vasculitis (AAV) patients.

Methods: We retrospectively reviewed the medical records of 160 patients with AAV. We calculated Birmingham vasculitis activity score (BVAS). We collected laboratory results including erythrocyte sedimentation rate (ESR), C-reactive protein (CRP), while blood cell, lymphocyte and platelet counts and serum albumin. Prognostic nutritional index (PNI) was calculated by (10 x serum albumin $(\mathrm{g} / \mathrm{dl})$ $+0.005 \times$ lymphocyte count $(/ \mathrm{mm} 3))$. The association was assessed linear regression analyses. The optimal cut-off of PNI for predicting relapse was set at 36.6 Comparison of cumulative relapse free survival was analysed by the KaplanMeier survival analysis.

Results: The mean age at diagnosis was 55.2 years and 48 patients were male. Eighty-five patients had MPA, 41 patients had GPA and 34 patients had EGPA The mean BVAS and PNI at diagnosis were 11.9 and 43.4. Forty-three patients experienced relapse of AAV. In univariable linear regression analysis, BVAS was positively correlated with ESR and CRP and was negatively correlated with lymphocyte count, serum albumin level and PNI. In multivariable analysis, BVAS was the most significantly associated with only PNI (standardised $\beta=-0.296$ ). Patients having $\mathrm{PNI}$ at diagnosis $\leq 36.6$ exhibited significantly lower cumulative relapse free survival rate than those having $\mathrm{PNI}$ at diagnosis $>36.6(p=0.002)$

Abstract SAT0547 - Table 3. Univariable linear regression analysis of BVAS and continuous variables in 160 patients with AAV

\begin{tabular}{|c|c|c|c|}
\hline & \multicolumn{3}{|c|}{ Univariable analysis } \\
\hline & $\begin{array}{c}\text { Regression } \\
\text { Coefficient } \\
\text { (Crude B) }\end{array}$ & $\begin{array}{c}\text { Correlation } \\
\text { Coefficient } \\
(R=\beta)\end{array}$ & $\begin{array}{c}p \\
\text { value }\end{array}$ \\
\hline \multicolumn{4}{|l|}{ Demographic data at diagnosis } \\
\hline Age (year old) & 0.027 & 0.053 & 0.504 \\
\hline \multicolumn{4}{|l|}{ Acute reactants at diagnosis } \\
\hline ESR (mm/hr) & 0.044 & 0.218 & 0.006 \\
\hline $\mathrm{CRP}(\mathrm{mg} / \mathrm{L})$ & 0.023 & 0.169 & 0.033 \\
\hline \multicolumn{4}{|c|}{$\begin{array}{l}\text { Laboratory results reflecting inflammation at } \\
\text { diagnosis }\end{array}$} \\
\hline White blood cell count $\left(/ \mathrm{mm}^{3}\right)$ & 0.000 & 0.104 & 0.189 \\
\hline Lymphocyte count $\left(/ \mathrm{mm}^{3}\right)$ & -0.002 & -0.214 & 0.007 \\
\hline Platelet count $\left(\times 1,000 / \mathrm{mm}^{3}\right)$ & 0.003 & 0.060 & 0.449 \\
\hline Serum albumin $(\mathrm{g} / \mathrm{dL})$ & -2.557 & -0.262 & 0.001 \\
\hline PNI & -0.252 & -0.307 & $<0.001$ \\
\hline
\end{tabular}

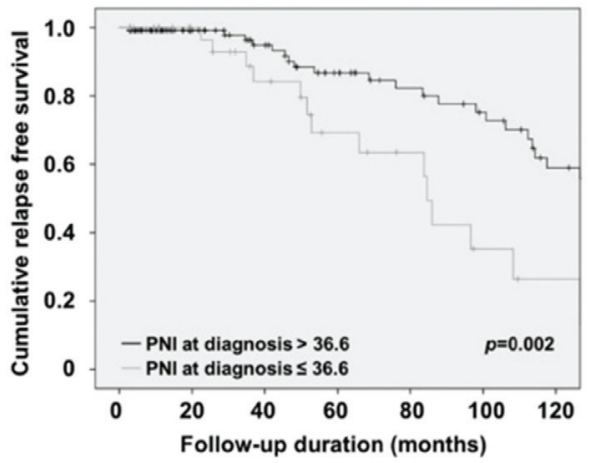

Abstract SAT0547 - Figure 2. The association of PNI at diagnosis with relapse of AAV during the follow-up. We selected the optimal cut-off of PNI at 36.6, divided patients into two groups according to the cut-off and conducted Kaplan-Meier survival analysis. Patients having PNI at diagnosis $\leq 36.6$ exhibited significantly lower cumulative relapse free survival rate than those having $\mathrm{PNI}$ at diagnosis $>36.6(p=0.002)$. $\mathrm{PNI}$ : prognostic nutritional index; AAV: antineutrophil cytoplasmic antibody. 